\title{
Animal models of anxiety: an ethological perspective
}

R.J. Rodgers, B.-J. Cao,

A. Dalvi and

A. Holmes
Ethopharmacology Laboratory, Department of Psychology,

University of Leeds, Leeds LS2 9JT, England
Correspondence

R.J. Rodgers

Ethopharmacology Laboratory

Department of Psychology

University of Leeds

Leeds LS2 9JT

England

Fax: 44 (113) 233-5749

E-mail: johnґ@sychology.leeds.ac.uk

Based on paper presented at the XI Annual Meeting of the

Federação de Sociedades de Biologia Experimental, Caxambu, MG, Brasil, August 21-24, 1996.

Research supported by the Medical Research Council, the Royal Society, the Wellcome Trust, and the University of Leeds. ......................

Received December 3, 1996

Accepted December 19, 1996

\begin{abstract}
In the field of anxiety research, animal models are used as screening tools in the search for compounds with therapeutic potential and as simulations for research on mechanisms underlying emotional behaviour. However, a solely pharmacological approach to the validation of such tests has resulted in distinct problems with their applicability to systems other than those involving the benzodiazepine/GABA $\mathrm{A}$ receptor complex. In this context, recent developments in our understanding of mammalian defensive behaviour have not only prompted the development of new models but also attempts to refine existing ones. The present review focuses on the application of ethological techniques to one of the most widely used animal models of anxiety, the elevated plus-maze paradigm. This fresh approach to an established test has revealed a hitherto unrecognized multidimensionality to plus-maze behaviour and, as it yields comprehensive behavioural profiles, has many advantages over conventional methodology. This assertion is supported by reference to recent work on the effects of diverse manipulations including psychosocial stress, benzodiazepines, GABA receptor ligands, neurosteroids, 5- $\mathrm{HT}_{1 \mathrm{~A}}$ receptor ligands, and panicolytic/panicogenic agents. On the basis of this review, it is suggested that other models of anxiety may well benefit from greater attention to behavioural detail.
\end{abstract}

\section{Introduction}

Animal models form the backbone of preclinical research on the neurobiology of psychiatric disorders, and are employed both as screening tools in the search for novel therapeutic agents and as simulations for studies on underlying mechanisms (1-8). More than 30 animal models of anxiety are currently in use and, while some are based on physiological (e.g., hyperthermia) or endocrine (e.g., plasma corticosterone) responses to stress, the vast majority are behavioural in nature. Behavioural models may
Key words

- Animal models of anxiety

- Ethology

- Defence

- Risk assessment

- Plus-maze

- Behavioural profiling

- Pharmacology conveniently be classified as either conditioned or unconditioned responses to stimuli which appear capable of causing anxiety in humans (Table 1). Although conditioning models permit fairly precise experimenter control over behavioural baselines, they often necessitate food or water deprivation, the use of electric shock and considerable time investment in the training of subjects. In contrast, while prone to more variable baselines, models involving unconditioned (i.e., spontaneous) behaviour generally have a higher degree of ecological validity, are less susceptible to confounds arising from 
interference with learning/memory, hunger/ thirst or nociceptive mechanisms and, at least in principle, allow for a truly comprehensive 'behavioural profiling' of experimental interventions.

In view of traditional approaches to the pharmacotherapy of human anxiety disorders, it is perhaps understandable that the major approach to validation of animal models of anxiety has been pharmacological. Thus, while many of these procedures have a reasonable degree of face validity, their major claim to status rests upon selective responsivity to agents with established efficacy in the clinical management of anxiety disorders (predictive validity). As benzodiazepines have been predominant in this field for almost 4 decades, pharmacological validation has, in practice, involved the use of chlordiazepoxide or diazepam as a 'gold standard'. Although this approach has worked well in identifying the anxiolytic potential of other benzodiazepine/GABA $\mathrm{A}_{\mathrm{A}}$ receptor-related agents ('me-same'), an obvious drawback is with the identification of compounds which may achieve anti-anxiety effects through unrelated mechanisms ('me-different'). An excellent example of the pitfalls of adopting a purely pharmacological approach to validation has been the general insensitivity of existing models to the clinically effective $5-\mathrm{HT}_{1 \mathrm{~A}}$ partial agonist, buspirone

Table 1 - Some commonly used animal models of anxiety.

Adapted from Refs. 1-8. dPAG, Dorsal periaqueductal gray matter.

\begin{tabular}{ll}
\hline Unconditioned responses & Conditioned responses \\
\hline Anxiety/defence test battery & Active/passive avoidance \\
Elevated plus-maze and zero-maze & Conditioned emotional response (CER) \\
Fear/defence test battery & Conditioned taste aversion \\
Free exploration & Conflict tests (pigeons and primates) \\
Holeboard & Defensive burying \\
Human threat (primates) & dPAG stimulation \\
Light/dark exploration & Fear potentiated startle \\
Open field & Four plate test \\
Social competition & Geller-Seifter conflict \\
Social interaction & Learned helplessness \\
Ultrasonic vocalization (pups) & Ultrasonic vocalization (adult)
\end{tabular}

$(3,5,7,8)$. Such problems have led to widespread (and, in our view, unwarranted) criticism of the models themselves rather than a more logical acceptance of the fact that "pharmacological validation alone does not make a test a model of anxiety' (4, p. 323) and that existing procedures should more accurately be considered 'models of benzodiazepine psychopharmacology' (2, p. 22).

The need for a new strategy in preclinical anxiety research is not only indicated by the apparent limitations of existing animal models, but also by the need for novel, safe and effective treatments for the full range of anxiety-related disorders. In this context, there has been growing medical and public concern about the side-effect profile of commonly prescribed benzodiazepine anxiolytics which, acutely, may include cognitive impairment and, chronically, the development of normal-dose dependence (9). In addition to these problems, which may or may not be manageable (10), it is widely acknowledged that the benzodiazepines are only truly effective in the treatment of one of the many anxiety-related conditions recognized in DSM-IV (11), i.e., generalized anxiety disorder. As such, there is also a demonstrable need for the development of animal models for different anxiety states and not just those which respond to benzodiazepines. Although it seems likely that existing models may, to a greater or lesser extent, already be tapping different facets of anxiety (1), it is not yet clear how individual tests relate to specific clinical conditions. Nevertheless, in considering the broader question of improvements in animal modelling, it seems prudent to bear in mind that a '....balance must be struck between the proliferation of newer models and the refinement of existing ones' $(12, \mathrm{p}$. 49).

\section{Defensive behaviour: a way forward}

Historically, it is somewhat paradoxical that attempts to develop animal models of 
anxiety have paid relatively little attention to behaviour or, more specifically, to the issue of behavioural validation. While acknowledging its hidden or subjective aspects, human anxiety is invariably reflected in overt behavioural disturbances including, for example, avoidance, escape, non-verbal vocalization and/or hypervigilance (13-15). When also observed in animals, such responses suggest (but of course do not prove) a common affective state. At minimum, therefore, the human and animal responses may be said to be analogous, thereby providing necessary face validity for the animal model. Construct validity, on the other hand, implies that the human and animal responses are homologous (common substrate) and, further, that the response in question has clinical significance for the disorder being modelled (16). Herein lies a significant problem in that, in the absence of a detailed understanding of the substrates of human anxiety, it becomes impossible to rigorously establish homology between animal and human response patterns. Nevertheless, the truly remarkable parallels between fear/anxiety reactions in humans and animals, together with the ease with which we seem able to empathize with frightened (as opposed to depressed or schizophrenic) animals, suggest that at least some animal response patterns may ultimately fulfil the homology criterion.

In The Expression of the Emotions in Man and Animals (1872), Charles Darwin (17) laid an important foundation for viewing the defensive patterns of other species as essential evolutionary precursors to human fear and anxiety reactions (18). More recently, a number of clinical accounts have conceptualized human anxiety disorders as disorders of defence (e.g., 19-22), in which the key feature concerns inappropriate activation of defensive behaviour arising from erroneous assessment of danger. As such, an understanding of the neurobiology of defensive behaviour assumes particular impor- tance in anxiety research and, in this context, recent studies have pointed to a remarkable similarity among vertebrates in the neural systems (e.g., amygdala, periaqueductal gray matter) involved in detecting danger and producing defence responses $(23,24)$. As this system is so strongly conserved in evolution, it has been convincingly argued that we can learn much about human defence or fear reactions by studying other creatures (25).

At the behavioural level, it has been known for quite some time (26) that animals are capable of displaying diverse defensive reactions in response to external threats, e.g., a predator or an aggressive conspecific. In mammals (e.g., rats), such behaviours classically comprise freezing, flight, defensive threat/attack and even death-feigning, and are dependent both upon threat imminence (27) and escape opportunity (28). This repertoire is most clearly observed in feral animals, although several features (e.g., freezing) may be elicited by appropriate stimulation of laboratory rats (29). However, recent research has shown that the rodent defensive repertoire is even more elaborate than suggested by this classical description. Thus, laboratory rats will bury dangerous objects (30), and emit ultrasonic vocalizations when injured (31), separated from their mother (32) or exposed to a natural predator (33). Furthermore, in potentially dangerous situations (for example, when a predator has been seen but is no longer present), laboratory rats (34) and mice (35) have been reported to engage in a cluster of behaviours collectively referred to as risk assessment. These responses, originally identified in specially constructed visible burrow systems, are characterized by cautious approaches to a surface area where a predator (cat) has briefly been presented and include i) scanning the danger area from tunnel openings, ii) stretched attend, or flatback, postures directed towards the danger area and iii) stretched, or flatback, locomotion upon initial re-entry into the danger area. Very simi- 
lar behaviour patterns have been observed in the rat defensive burying paradigm $(36,37)$ and in mice exposed to conspecific odours $(38,39)$, supporting the contention that their function is to inform behavioural strategy in potentially dangerous situations $(18,40)$. As many animal models of anxiety are based upon exploration of novel (and, hence, potentially dangerous) environments, it would be predicted that these situations should also elicit risk assessment. Recent work in our laboratory and elsewhere has confirmed this prediction.

\section{The elevated plus-maze}

The elevated plus-maze is undoubtedly one of the most widely used animal models in contemporary preclinical research on anxiety $(5,41)$. This test derives from the early observation that, in mazes consisting of open and closed alleys, rats consistently show higher levels of exploration in enclosed alleys and, when faced with a choice of alley type, typically avoid those without walls (42). Some 30 years later, this finding led to the first studies on the potential utility of an elevated ' $\mathrm{X}$ '-maze as a model of anxiety (43). Using a simple maze configuration, elevated $70 \mathrm{~cm}$ above floor level and comprising two open and two enclosed arms (like arms opposing one another), these authors not only confirmed that rats avoid the open arms but also demonstrated that open arm avoidance is reduced by diazepam and enhanced by picrotoxin (an anxiogenic agent). Comprehensive validations of the test (now termed the elevated 'plus'-maze) for use with both rats (44) and mice (45) quickly followed this initial report, and more recent research has suggested its potential utility for other species including guinea pigs (46), wild voles (47) and Syrian hamsters (48). From the outset, the primary indices of anxiety in the plus-maze have been spatiotemporal in nature (i.e., the number of open arm entries expressed as a percentage or ratio of total arm entries, and time spent on the open arms expressed as a percentage or ratio of total arm time), while total arm entries have frequently (but erroneously, see below) been employed as a measure of general activity.

The advantages of the conventional elevated plus-maze are obvious and numerous: ecological validity, economy, speed, simplicity and bidirectional sensitivity coupled with the fact that the procedure does not require lengthy training procedures involving the use of food/water deprivation and electric shock (44). However, while there is no doubt that the conventional plus-maze is highly sensitive to the influence of benzodiazepine/GABA $\mathrm{A}_{\mathrm{A}}$ receptor-related manipulations, effects obtained with other anxietymodulating agents (e.g., buspirone) have been very much more variable $(5,8,49)$. Although this profile has led certain authors to doubt the utility/reliability of the model $(50,51)$, alternate interpretations of this pharmacological inconsistency are just as plausible. As already noted, the way in which tests such as the plus-maze were originally developed (i.e., benzodiazepine criterion) provided excellent tools for detecting benzodiazepine/ GABA-related compounds and it would seem churlish, to say the least, to criticize them for relative insensitivity to agents operating through entirely different mechanisms. This (not irrelevant) point aside, negative and/or contradictory findings with buspirone may arise from the use of inappropriate dose ranges (e.g., the issue of pre- $v s$ post-synaptic sites of action) or, indeed, from the fact that animal studies more often than not involve acute administration whereas clinical experience would indicate therapeutic efficacy only after several weeks of treatment (see also 52). In our view, an equally important consideration arises, somewhat paradoxically, from the aforementioned advantages of the plus-maze paradigm. Thus, the fact that a maze is readily constructed, sessions are short (5 $\mathrm{min}$ ) and conventional scoring is 
both fast and easy has been instrumental in the adoption of the test by numerous research laboratories (at least 100 according to a recent survey; 41). Unfortunately, in the same way tradition holds that there are as many psychologies as there are psychologists, there are probably as many plus-maze 'paradigms' as there are laboratories conducting preclinical research on anxiety.

Major inter-laboratory differences therefore exist in the use of the plus-maze paradigm, and these encompass a wide range of organismic and procedural variables (Table 2; see also 5). This point is very firmly emphasized in a recent survey of 65 'plusmaze laboratories', the results of which clearly show that pharmacological response is heavily influenced by choice of strain, pretest manipulation of subjects and the aversiveness of the test conditions (41). For example, it would appear that sensitivity to potential (particularly non-benzodiazepine) anxiolytics is enhanced by stressing animals prior to testing (e.g., by moving from holding to test room) and/or by using more aversive test conditions (e.g., high light), thereby suggesting the fundamental importance of endogenous tone in key neurochemical systems. It is therefore essential that laboratories using, or planning to use, the plus-maze invest sufficient time and effort in defining optimal test conditions prior to drug studies. In view of these considerations, the importance of response baselines in behavioural pharmacology and the fact that conventional plus-maze scoring actually pays minimal attention to actual behaviour, several research groups have argued that the utility/reliability/sensitivity of this model might also be improved by adopting a more ethological approach to data collection (e.g., 50,53-56).

\section{Behavioural profiling in the plus-maze}

In considering alternate approaches to the study of animal behaviour, the German ethologist Konrad Lorenz (57) referred to the fashionable fallacy of dispensing with description. The implicit criticism of limited analysis is also apparent in the writings of the Dutch ethologist, Niko Tinbergen (58), who insisted that the first task in any behavioural study ought to be the observation and description of the full behavioural repertoire of the species under study. In a similar fashion, the British ethologist W.H. Thorpe (59) cogently argued that the closer the initial rapport a behavioural scientist can establish with the animal he is studying, the more successful his investigations are likely to be. In the present context, the benefits of this general philosophy are clearly evident in the elegant work of the Blanchards (reviewed above) on defensive patterns in rats and mice, work that has led to important developments in contemporary approaches to research on the neurobiology of fear and anxiety.

Over the past 6 years, we have developed a procedure that allows for the comprehensive 'profiling' of behaviour in the murine elevated plus-maze paradigm. This approach was stimulated by advances in our understanding of the rodent defensive repertoire, several years of experience in using conventional plus-maze methodology (60), and preliminary evidence that rodents display at least some defensive elements in this test (e.g., freezing, defaecation, and stretched attend postures (SAP); 44,50). Detailed vid-

Table 2 - Some sources of inter-laboratory variation in use of the elevated plus-maze paradigm.

\footnotetext{
Species, strain, age and gender

Housing conditions and light cycle

Prior handling and injection experience Prior maze experience

Prior exposure to holeboard/activity test

Adaptation to test laboratory

Time of testing and lighting level

Presence of experimenter in test room

Method of scoring, e.g., live, manual/automated, videotape

Definition of measures, e.g., arm entry

Validation of measures

Measures scored: conventional, ethological
}

Maze construction, e.g., opaque/transparent walls, open arm ledges 
eotape analysis of the behaviour patterns of untreated mice on the maze, initially conducted using manual event recorders/timers, yielded a catalogue of readily identifiable behaviours including rearing, head-dipping, stretched attend postures and closed arm returns (i.e., doubling back, rather than leaving, a closed arm) as well as several nonexploratory behaviours (61). In addition, it was noted that the spatial distribution of certain acts and postures (i.e., head-dipping, SAP) appeared to be dependent upon contact with the maze walls, leading us to differentiate 'protected' (wall contact in closed arms and/or central platform) and 'unprotected' (no wall contact, i.e., on open arms) forms of these behaviours. This differentiation agrees well with subsequent studies by Treit et al. (62) in Canada which confirmed that the most important maze feature producing open arm avoidance is the absence of walls (i.e., the absence of thigmotactic cues) and not, as might have been suspected, the height of the maze above floor level.

Most research techniques evolve over time, usually through a combination of trial/

Table 3 - Behaviours recorded in the ethological plus-maze, grouped according to factor analysis (subjects, male DBA/2 mice).

All factor loadings $\geq 0.40$, with highest loading elements emboldened. Total variance accounted for $=76.1 \%$. For full details, see Ref. $63 .{ }^{*} \%$ open entries $=$ (open entries/ total entries) $\times 100 ; \%$ time $=$ (time in area/session length in s) $\times 100 ; \%$ protected scores $=($ protected $/$ total $) \times 100$.

\begin{tabular}{|c|c|c|}
\hline Factor & Interpretation & Behavioural elements* \\
\hline 1 & 'Anxiety' & $\begin{array}{l}\text { Total arm entries, open arm entries, \% open entries, } \\
\% \text { open time, \% closed time (-), \% centre time }(-) \text {, } \\
\text { closed arm returns }(-), \% \text { protected head-dipping }(-) \text {, } \\
\% \text { protected SAP (-), \% protected sniffing }(-) \text { and } \% \\
\text { protected flatback approach }(-)\end{array}$ \\
\hline 2 & 'Locomotion' & $\begin{array}{l}\text { Total arm entries, closed arm entries, total } \\
\text { flatback approach }\end{array}$ \\
\hline 3 & 'Risk assessment' & Total SAP, total sniffing \\
\hline 4 & 'Decision-making' & $\begin{array}{l}\text { Closed arm returns }(-) \text {, grooming }(-), \% \text { centre } \\
\text { time, \% closed time (-) }\end{array}$ \\
\hline 5 & $\begin{array}{l}\text { 'Vertical activity' } \\
\text { 'Exploration' }\end{array}$ & $\begin{array}{l}\text { Total arm entries, closed arm entries, rear } \\
\text { frequency, rear duration, grooming }(-) \\
\text { Total head-dips, total SAP }\end{array}$ \\
\hline
\end{tabular}

error and technical innovation. On the trial and error side, we have found that by repositioning the videocamera (from directly overhead to an angle of ca. $50^{\circ}$ ), our ability to discriminate non-exploratory behaviours (i.e., immobility, grooming) was markedly improved as was our ability to accurately score additional behavioural elements (e.g., sniffing, flatback approach). This work has been greatly facilitated by the adoption of ethological analysis software ('Hindsight', a package developed by Dr. Scott Weiss) which permits direct keyboard entry to a PC using separate keys for location and behaviour. The datafiles created cannot only be easily downloaded for standard statistical analyses (i.e., group differences) but are also amenable to reconfiguration thereby permitting the execution of more detailed analysis, e.g., minute-by-minute behavioural changes. Table 3 summarizes the various spatiotemporal and behavioural measures now routinely recorded in our laboratory, grouped according to the outcome of a recent factor analytic study on a large cohort of undrugged DBA/2 mice. This analysis identified a 6factor structure accounting for $>75 \%$ of the total variance (63).

In close agreement with earlier factor analyses in both mice (45) and rats (1), the primary indices of anxiety and locomotor activity loaded on separate factors (Factors 1 and 2 , respectively). In this context, the 'protected' forms (\%p values) of head-dipping, SAP, sniffing, and flatback approach also loaded highly on Factor 1, confirming their close relationship to open arm avoidance. In contrast, closed arm entries loaded highly and exclusively on Factor 2, confirming the superiority of this measure ( $v s$ total entries) as an index of locomotor activity (see also 1,45,64-66). However, unlike previous factor analyses based solely on conventional measures, the incorporation of specific behavioural acts and postures revealed four additional dimensions to behaviour displayed in the maze. It is particularly interesting to 
note that $\%$ time spent on the centre platform (Factor 4, 'decision-making') and total SAP (Factor 3, 'risk assessment') loaded on factors other than the main 'anxiety' factor (Factor 1), and that rearing (Factor 5, 'vertical activity') and head-dipping (Factor 6, 'directed exploration') loaded separately from locomotor activity (Factor 2). Although differing somewhat in specific details, similar multidimensionality has been revealed in recent ethological studies of rat behaviour in the plus-maze (64-66). However, as strain comparisons in mice have not only suggested that basal plus-maze profiles differ quantitatively $(67,68)$ but also qualitatively (i.e., factor structure; 69), caution should be exercised in too readily applying knowledge of behavioural structure from one strain/ species to another.

This new conceptualization of response patterns in the plus-maze offers several potential advantages in the interpretation of treatment effects in this model. For example, in DBA/2 mice, the apparent independence of measures related to avoidance (Factor 1), risk assessment (Factor 3) and decision-making (Factor 4) would clearly suggest the possibility of dissecting treatment effects on different components of the affective state induced by exposure to the maze. Furthermore, the important issue of behavioural specificity, normally addressed by examining treatment effects on closed arm entries (Factor 2), may also be approached by examining treatment effects on other active behaviours such as rearing (Factor 5) and head-dipping (Factor 6). As in other areas of ethopharmacology, e.g., research on agonistic behaviour (70), such interpretation should be guided by the overall behavioural profile and not by dogmatic adherence to preconceptions regarding the importance of any single variable. A hypothetical example may help to convey this point more clearly. Assume that drug ' $X$ ' produces an anxiolyticlike increase in the frequency and duration of open arm visits yet significantly reduces closed arm entries and rearing. It might be inferred from this pattern of behavioural change that drug ' $X$ ' has had a non-selective behavioural (e.g., sedative) action. However, if we add into the equation that total arm entries remained unchanged and knowledge that virtually all rearing occurs in the closed arms, this hypothetical drug profile might instead suggest a treatment-induced redistribution of exploratory behaviour (i.e., increased open arm entries plus decreased closed entries $=$ no change in total; decreased closed arm entries $=$ reduced opportunity for rearing). Furthermore, should the hypothetical profile also indicate an apparent increase in head-dipping and no change in immobility scores, an interpretation in terms of behavioural non-selectivity becomes even more untenable. The following section provides some concrete examples of the advantages of behavioural profiling in the murine plusmaze.

\section{Research findings}

Psychosocial stress. Social stress, in the form of defeat experience, is a potent stimulus in activating non-opioid analgesia mechanisms in mice (71), with both behavioural (72) and pharmacological (73-77) evidence pointing to anxiety as a key factor in this anticipatory defence reaction. In confirmation of this hypothesis, immediate prior social defeat (and, to a lesser extent, exposure to the scent of an aggressive male conspecific) was found to produce a significant anxiogenic-like effect in the murine plusmaze (78). This enhancement of anxiety was evident on both conventional open arm avoidance measures as well as several ethological measures, including SAP and closed arm returns. Not only is this finding consistent with the anxiety hypothesis of non-opioid defeat analgesia but it also shows that the plus-maze is sensitive to biologically meaningful, as well as artificial 'stressors' (5). Importantly, the observed stress-induced 
changes in measures related to anxiety were accompanied by significant behavioural suppression indicating that care should be taken in the interpretation of certain drug profiles. In particular, when considering the action of anxiogenic drugs, reduced behavioural output should not automatically be taken as evidence of behavioural non-selectivity. Afterall, movement inhibition is a characteristic of very frightened animals (28).

Benzodiazepines. Studies from our laboratory have confirmed that full and partial benzodiazepine receptor agonists produce behavioural changes in the maze consistent with anxiety reduction (79-81). Typically, these agents reduce open arm avoidance and risk assessment (e.g., SAP) measures while enhancing exploratory head-dipping. Such changes generally occur at doses which do not suppress general activity, and are apparent following both acute (79-81) and chronic (82) treatment. However, while higher doses of chlordiazepoxide and diazepam may increase immobility scores, no such changes were observed with the partial agonist, bretazenil. This comparison indicates that current methods are able to discriminate compounds from the same general class (see also section on 5- $\mathrm{HT}_{1 \mathrm{~A}}$ receptor ligands), and that partial agonists may indeed be behaviourally more selective than full agonists. Furthermore, and as has since been reported for the rat 'zero-maze' (an annular variant of the plus-maze with alternating open/closed quadrants; 83) and rat plus-maze (84), benzodiazepine-induced reductions in risk assessment tend to occur at doses below those required to significantly increase open arm activity. This finding suggests that, as for enhanced head-dipping, reductions in risk assessment may be a particularly sensitive marker for benzodiazepine-like behavioural activity. Finally, and as would be predicted on the basis of bidirectional control of anxiety via the benzodiazepine/GABA ${ }_{\mathrm{A}}$ complex, compounds acting as inverse agonists at this site (e.g. FG 7142) produce anxiogenic-like ef- fects in the plus-maze though, interestingly, changes in risk assessment are less apparent (ceiling effect?) than changes in open arm avoidance (85).

$G A B A_{A}$ receptor ligands. Although it is widely held that benzodiazepine anxiolytics exert their behavioural effects through a facilitation of $\mathrm{GABA}_{\mathrm{A}}$ receptor function, the effects of direct GABAergic manipulations in animal models of anxiety are actually highly variable. However, recent studies from our laboratory $(86,87)$ have shown that, in contrast to the lack of specific effect of a $\mathrm{GABA}_{B}$ receptor agonist $(\mathrm{R}(+)$ baclofen $)$ and a $\mathrm{GABA}_{\mathrm{B}}$ receptor antagonist (CGP35348), indirect facilitation of GABA function (sodium valproate) or direct $\mathrm{GABA}_{\mathrm{A}}$ receptor stimulation (muscimol) produces a behaviourally selective and diazepam-like anxiolytic profile in the murine plus-maze. Furthermore, $\mathrm{GABA}_{\mathrm{A}}$ antagonists, such as picrotoxin (86) and pentylenetetrazole (85), produced clear evidence of anxiogenic-like activity accompanied, at high doses, by behavioural suppression. Intriguingly, comparatively low doses $(2-4 \mathrm{mg} / \mathrm{kg}$ ) of pentylenetetrazole ( $v s$ an anxiogenic dose of $20 \mathrm{mg} / \mathrm{kg}$ ) were associated with an anxiolytic-like profile, a finding that clearly merits further research.

Neurosteroids. Certain steroids, including $5 \alpha$ - and $5 \beta$-reduced metabolites of progesterone and deoxycorticosterone, are known to exert rapid, non-genomic effects in the CNS through allosteric modulation of $\mathrm{GABA}_{\mathrm{A}}$-mediated chloride influx (88). In this context, very recent work in our laboratory (89) has revealed significant anxiolyticlike activity for the deoxycorticosterone metabolite, 3 $\alpha$-tetrahydrodeoxycorticosterone (THDOC) as well as the progesterone metabolites, pregnanolone and $3 \alpha$ - (but not 3B-) allopregnanolone. Further work has shown that an intermediate metabolite of progesterone, 5ß-dihydroprogesterone (DHP), also produces an anxiolytic profile whereas 5 $\alpha$-DHP does not (90). The behav- 
ioural profiles of the active steroids are very similar to those seen with benzodiazepine anxiolytics, valproate and muscimol (see above), providing some support for mediation through the $\mathrm{GABA}_{\mathrm{A}}$ receptor complex. However, further studies are required to confirm this presumed mechanism of action.

Serenics. The term 'serenic' has been coined to describe the effects of a group of 5HT receptor ligands which, it is argued, selectively inhibit offensive aggression (91). Although apparently producing this effect in the absence of sedation or psychomotor stimulation, evidence from tests not involving aggression (92) suggests that these agents may increase defence/fear. To further test this hypothesis, we examined the effects of two serenic compounds, fluprazine and eltoprazine, in the murine plus-maze. For comparative purposes, and particularly in view of similarities in affinity for and action at 5-HT receptor subtypes $\left(5-\mathrm{HT}_{1 \mathrm{~B}}\right.$ and 5$\mathrm{HT}_{2 \mathrm{C}}$ ), parallel studies with the well-known 5-HT anxiogenic agents, mCPP and TFMPP, were also conducted (61). Although none of the test compounds produced convincing effects on conventional plus-maze anxiety indices (i.e., \% open entries, and \% open time), all markedly increased SAP, percent protected forms of SAP and head-dipping, and closed arm returns. These effects were strongly dose-dependent and apparent at dose levels below those producing significant behavioural suppression. Apart from confirming that serenics can indeed enhance anxiety/fear-related behaviours, this study importantly emphasizes that the current methodology is sensitive to changes in affective state that are not necessarily revealed by conventional measures.

5-HT $T_{I A}$ receptor ligands. As reviewed above, the vast majority of animal models of anxiety have yielded inconsistent and often contradictory profiles for $5-\mathrm{HT}_{1 \mathrm{~A}}$ receptor agonists/partial agonists such as 8-OH-DPAT and buspirone. The plus-maze is no exception to this 'rule' in that the full range of effects from anxiolysis through neutrality to anxiogenesis have been reported $(5,8)$. However, ethological analysis has revealed an anxiolytic-like effect with both acute and chronic buspirone in the murine plus-maze (93). At doses of $2.5-5.0 \mathrm{mg} / \mathrm{kg}$, acutely administered buspirone induces an anxiolytic-like effect on conventional open arm avoidance measures coupled with a profound suppression of most active behaviours (both actions more evident after chronic treatment). However, at lower doses, significant anxiolytic-like effects were observed on several ethological measures, including reductions in risk assessment (see also 94 for comparable findings in rat plus-maze). Although we have also observed a generally similar profile with another 5-HT $1 \mathrm{~A}$ receptor agonist, flesinoxan (95), some potentially important within-class differences were apparent. For example, whereas the behavioural suppression induced by high-dose buspirone treatment was associated with prolonged bouts of immobility (a dopaminergic effect?), this was not observed with high-dose flesinoxan treatment which, instead, appeared to reduce the overall rate of behaviour. Although some weak anxiolytic-like activity has also been seen with $( \pm)-8-O H-D P A T$, the predominant effect of this compound is also to reduce behavioural output (61). Very recent work from our laboratory has shown that the motoric effects of this prototypical $5-\mathrm{HT}_{1 \mathrm{~A}}$ receptor ligand reside in its $\mathrm{R}(+)$ enantiomer (full agonist), whereas any weak anxiolytic-like action seems to be due to the action of the S(-)-enantiomer (partial agonist) (96).

Considerable debate continues regarding the mechanism whereby buspirone achieves its anti-anxiety action although it is generally agreed that it relates to a reduction in 5HT neurotransmission (97). Suggestions as to how such an effect might be achieved range from an agonist action at somatodendritic 5-HT $1 \mathrm{~A}$ autoreceptors, through an antagonist action at post-synaptic $5-\mathrm{HT}_{1 \mathrm{~A}}$ re- 
Table 4 - Compounds with 5-HT1 A antagonist activity, dose ranges studied, and control compounds tested.

For details, see text and Refs. 100-102.

Compound Dose range $(\mathrm{mg} / \mathrm{kg})$

$\begin{array}{lc}\text { (-)Pindolol } & 0.1-6.4 \\ \text { Pindobind 5-HT } & \\ \text { 1A } & 0.1-2.5 \\ \text { WAY 100135 } & 2.5-20.0 \\ \text { WAY 100635 } & 0.03-9.0 \\ \text { pMPPI } & 0.5-13.5 \\ \text { SDZ 216-525 } & 0.05-3.2 \\ \text { NAN-190 } & 0.1-10.0 \\ & \\ \text { (+) Pindolol } & 0.1-6.4 \\ \text { Metoprolol }\left(ß_{1}\right) & 2.0-18.0 \\ \text { ICl-118,551 }\left(\beta_{2}\right) & 1.0-9.0 \\ \text { Prazosin }\left(\alpha_{1}\right) & 0.02-2.5\end{array}$

ceptors, to a combination of both effects (98). Following preliminary and positive observations with (S)-WAY 100135 (99), we have recently explored further the possibility that $5-\mathrm{HT}_{1 \mathrm{~A}}$ receptor blockade would produce an anti-anxiety profile in the murine plus-maze model. To this end, we have studied a range of compounds which (with varying degrees of selectivity) exert antagonistic effects at these receptors. Table 4 lists those agents/doses studied to date, together with compounds used as controls for additional pharmacological actions.

Our results, some of which are 'in press', have revealed that, despite variation in chemical structure and degree of selectivity for 5$\mathrm{HT}_{1 \mathrm{~A}}$ receptors, these agents share in common an ability to reduce anxiety in SwissWebster mice (100-102). In brief, anxiolyticlike effects on both conventional and ethological indices have been observed with (-)pindolol, pindobind 5- $\mathrm{HT}_{1 \mathrm{~A}}$, SDZ 216525, WAY 100635 and pMPPI. Importantly, in view of pharmacological specificity, no such effects were observed with wide dose ranges of $(+)$ pindolol, metoprolol $\left(\beta_{1}\right.$-antagonist), ICI-118,551 ( $\beta_{2}$-antagonist) or prazosin $\left(\alpha_{1}\right.$-antagonist). Furthermore, both NAN-190 (mixed 5-HT $\mathrm{HA}_{1 \mathrm{~A}} / \alpha_{1}$ ) and buspirone (partial agonist) were devoid of convincing anxio- lytic activity in these studies, largely suppressing active behaviours at the highest doses used. The dose-response profiles of the 5-HT ${ }_{1 \mathrm{~A}}$ antagonists were invariably bellshaped, with either loss of activity or behavioural non-specificity evident at higher doses. Together, these results are very encouraging, particularly in view of the wide dose separation for anxiolytic and motoric effects (a pattern very different to that observed with full and partial $5-\mathrm{HT}_{1 \mathrm{~A}}$ receptor agonists). However, although our findings suggest therapeutic potential for $5-\mathrm{HT}_{1 \mathrm{~A}}$ antagonists in the management of anxiety disorders, the issue of a pre- versus post-synaptic action remains open. Thus, while traditional views on 5-HT and anxiety would suggest a post-synaptic locus (i.e., reduction in 5-HT transmission), empirical support must be obtained through studies on the effects of direct antagonist application to sites such as the raphe nuclei and hippocampus. In this context, it is worth noting that anxiolyticlike effects have been reported in several rat models following intrahippocampal injection of the mixed 5-HT $\mathrm{HA}_{1 \mathrm{~A}}$ antagonist/Bblocker tertatolol (103), while hippocampal and amygdaloid injections of 8-OH-DPAT have been found to enhance anxiety $(104,105)$. However, the fact that $5-\mathrm{HT}_{1 \mathrm{~A}}$ receptor manipulations would appear to have more consistent effects in mouse ( $v s$ rat) models of anxiety (e.g., 5,8,100-102) and that a clear species difference exists in 5$\mathrm{HT}_{1 \mathrm{~A}}$ receptor-mediated physiological responses (e.g., 8-OH-DPAT-induced hypothermia: pre-synaptic in mouse but postsynaptic in rat, 106) would caution against over-interpretation of these findings.

Antidepressant/antipanic agents. It has been known for some time that panic disorder responds much better to certain antidepressants (phenelzine and imipramine) than to traditional anxiolytic agents $(107,108)$. More recent research has suggested that second-generation antidepressants, in particular the serotonin-selective reuptake inhibi- 
tors (SSRI), are also effective in this regard and may actually have therapeutic advantage over conventional tricyclics $(109,110)$. However, neither acute nor chronic imipramine treatment was found to alter anxiety indices in the murine plus-maze (81), with negative results also reported for chronic fluvoxamine (SSRI) treatment (82). In contrast, low doses of the noradrenaline-selective reuptake blocker, maprotiline, did produce a selective reduction in open arm avoidance (82), suggesting possible therapeutic application in anxiety and/or anxious-depression. Surprisingly, the atypical antidepressant, tianeptine, was seen to produce anxiogenic-like changes in behaviour following subchronic treatment in the plusmaze and social interaction paradigms (111). Although this finding would not be inconsistent with its presumed mechanism of action (enhancement of 5-HT reuptake), it is puzzling in view of its use (at least in France) as a prescription medication. Nevertheless, the lack of efficacy of imipramine and fluvoxamine under present test conditions would suggest that the murine plus-maze is not sensitive to compounds with established clinical efficacy in the management of panic disorder. This conclusion is further supported by our recent observation that several $\mathrm{CCK}_{\mathrm{B}}$ receptor antagonists (L-365260, PD135158), thought to have potential as antipanic agents, are also ineffective over wide dose ranges (80).

Pro-anxiety/panicogenic agents. Reference has already been made to the anxiogeniclike effects of 5- $\mathrm{HT}_{1 \mathrm{~B} / 2 \mathrm{C}}$ agonists (TFMPP, $\mathrm{mCPP}$ ) (61), benzodiazepine receptor inverse agonists (FG 7142) (85) and $\mathrm{GABA}_{\mathrm{A}}$ receptor antagonists (picrotoxin, PTZ) $(85,86)$ in the present model. However, we have failed to observe any consistent signs of anxiety enhancement with the putative panicogenic agents, CCK-4 and CCK-8 (80), as well as isoproterenol and sodium lactate (85). These findings not only confirm the differential sensitivity of the murine plus-maze to anxi- ety modulation, but also allow a firmer characterization of the procedure as one perhaps more suited to screening of compounds for clinical potential in the treatment of generalized anxiety disorder and to related mechanistic studies. However, it should be noted that this conclusion may well only apply to use of the model with test-naive animals in that we have recently obtained evidence (69) that, as for rats (112), the nature of the anxiety response displayed in test-experienced mice differs qualitatively from that seen in test-naive subjects. In view of the possible implications of this finding, behavioural and pharmacological studies on 'retest anxiety' are eagerly awaited.

Miscellaneous. The utility of an animal model of anxiety rests not only in its ability to detect bidirectional changes in anxiety with established and putative anxiolytics/ anxiogenics, but also in i) excluding compounds that are either inactive or non-specific in behavioural action, and ii) highlighting novel (perhaps unexpected) drug effects that may provide fresh insights into mechanisms involved in the modulation of affective behaviour. Inactive compounds in the murine plus-maze include: the $5-\mathrm{HT}_{2 \mathrm{~A} / \mathrm{C}}$ ligands, ritanserin and DOI (113); the 5- $\mathrm{HT}_{3}$ receptor antagonists, ondansetron and WAY 100289 $(111,114)$; the peripherally acting antimuscarinic, methyl scopolamine (115); and the dopamine $\mathrm{D}_{1}$ receptor agonist, SKF38393 (116). Compounds found to produce behaviourally non-selective effects include the $\mathrm{GABA}_{\mathrm{B}}$ agonist (+)baclofen and the GABA reuptake blocker, No-711 (86); the $\alpha_{2}$ adrenoceptor agonist, clonidine (117); the neuroleptic, haloperidol (94); the $\mathrm{D}_{1}$ receptor antagonist, $\mathrm{SCH} 23390$ (116); and the $\mathrm{D}_{3 /}$ ${ }_{2}$ receptor agonists, quinpirole (116) and 7OH-DPAT (118).

The present model has also produced some unexpected findings. For example, the centrally acting antimuscarinic, scopolamine hydrobromide, was found to produce an anxiogenic-like profile (116). As the major 
change induced by this agent was a marked increase in risk assessment, an action on more cognitively related, information-processing mechanisms seems probable. We have also found that, unlike haloperidol, the atypical antipsychotic sulpiride has quite pronounced anti-anxiety effects in our model (116). This finding confirms a similar report from Costall's group (119) based on the mouse light/dark exploration model, and certainly deserves further research attention. Finally, in direct contrast to expectation, the 'well-known anxiogenic agent', yohimbine, actually produces a plus-maze profile consistent with an unambiguous anxiolytic action (117). Although it might be argued that this finding is problematic for the present methodology, it should be noted that a) similar anti-anxiety effects have been seen with yohimbine in other animal models, b) the effects in the plus-maze are seen in 3 mouse strains, c) yohimbine has high affinity for sites (e.g., $5-\mathrm{HT}_{1 \mathrm{~A}}$ ) other than $\alpha_{2}$-adrenoceptors, and d) more selective $\alpha_{2}$-antagonists (e.g., idazoxan) are relatively ineffective in the present model (117). This analysis suggests that, under certain test conditions (e.g., high background stress?), yohimbine may preferentially influence non-adrenergic mechanisms to achieve its apparent antianxiety action.

\section{Conclusion}

It is hoped that this brief review has convinced the reader of the value of an ethological approach to the elevated plus-maze test. Although it may appear that our analytic technique demands substantially greater time investment than conventional scoring (51), full behavioural profiling of the type described above (based on real-time, and computer-assisted videotape scoring) actually only requires a total of 10 min per subject (5 min test +5 min scoring). Less comprehensive ethological analysis (e.g., scoring only head-dipping and SAP in addition to conventional measures) has been successfully adopted for the rat 'zero-maze' paradigm (83) and has been reported not to involve any significant additional time (120).

Whatever additional time investment may be needed for ethological analysis, this is more than adequately compensated by the multiple advantages of this approach. These may be summarised as i) increased face and construct validity, ii) comprehensive 'profiling' of compounds, thereby greatly facilitating conclusions regarding behavioural specificity and permitting fine-grain comparisons within as well as between drug classes, iii) reducing or eliminating the need for additional tests (resource implications) to control for treatment effects on general activity, appetite, thirst and/or nociception, and iv) enhanced sensitivity to drug action as evidenced by the utility of risk assessment measures. Although obvious progress has recently been made in extending the principle of 'behavioural profiling' to the rat zero-maze and plus-maze paradigms, it is particularly important to note the demonstrable utility of ethological measures in more clearly characterizing drug effects in the defensive burying paradigm (37). In view of these findings, is it not now time to abandon the 'quick fix' approach to modelling, and extend ethological analysis to other established animal tests of anxiety? 


\section{References}

1. File SE (1992). Behavioural detection of anxiolytic action. In: Elliott JM, Heal DJ \& Marsden CA (Editors), Experimental Approaches to Anxiety and Depression. Wiley, Chichester, 25-44.

2. Green $S \&$ Hodges $H$ (1991). Animal models of anxiety. In: Willner $\mathrm{P}$ (Editor), Behavioural Models in Psychopharmacology. CUP, Cambridge, 21-49.

3. Handley SL (1991). Serotonin in animal models of anxiety: the importance of stimulus and response. In: Idzikowski C \& Cowen P (Editors), Serotonin, Sleep and Mental Disorder. Wrightson Biomedical, Petersfield, 89-115.

4. Lister RG (1990). Ethologically-based animal models of anxiety disorders. Pharmacology and Therapeutics, 46: 321-340.

5. Rodgers RJ \& Cole JC (1994). The elevated plus-maze: pharmacology, methodology and ethology. In: Cooper SJ \& Hendrie CA (Editors), Ethology and Psychopharmacology. Wiley, Chichester, 944.

6. Stephens DN \& Andrews JS (1991). Screening for anxiolytic drugs. In: Willner $\mathrm{P}$ (Editor), Behavioural Models in Psychopharmacology. CUP, Cambridge, 50-75.

7. Treit D (1994). Animal models of anxiety and anxiolytic drug action. In: den Boer JA \& Sitsen JMA (Editors), Handbook of Depression and Anxiety. Marcel Dekker, New York, 201-224.

8. Griebel G (1995). 5-Hydroxytryptamine-interacting drugs in animal models of anxiety disorders: more than 30 years of research. Pharmacology and Therapeutics, 65: 319-395

9. Lader MH (1991). Benzodiazepines and novel anxiolytics: clinical pharmacology, dependence and withdrawal. In: Rodgers RJ \& Cooper SJ (Editors), 5-HT $1 A$ Agonists, 5- $\mathrm{HT}_{3}$ Antagonists and Benzodiazepines: Their Behavioural Pharmacology. Wiley, Chichester, 343-363.

10. Ashton $\mathrm{H}$ (1994). Guidelines for the rational use of benzodiazepines. Drugs, 48: 25-40.

11. American Psychiatric Association (1994). DSM-IV. APA, Washington DC.

12. Barrett JE (1991). Animal behaviour models in the analysis and understanding of anxiolytic drugs acting at serotonin receptors. In: Olivier B, Mos J \& Slangen JL (Editors), Animal Models in Psychopharmacology. Birkhäuser, Basel, 37-57.
13. Beck AT \& Emery G (1985). Anxiety Disorders and Phobias: A Cognitive Perspective. Basic Books, New York.

14. Marks IM (1987). Fears, Phobias, and Rituals: Panic, Anxiety and their Disorders. OUP, New York.

15. Eysenck MW (1991). Cognitive factors in clinical anxiety: potential relevance to therapy. In: Briley M \& File SE (Editors), New Concepts in Anxiety. Macmillan Press, London, 418-433.

16. Willner $P$ (1991). Behavioural models in psychopharmacology. In: Willner P (Editor), Behavioural Models in Psychopharmacology. CUP, Cambridge, 3-18.

17. Darwin CR (1872). The Expression of the Emotions in Man and Animals. John Murray, London.

18. Blanchard DC, Blanchard RJ \& Rodgers RJ (1991). Risk assessment and animal models of anxiety. In: Olivier B, Mos J \& Slangen JL (Editors), Animal Models in Psychopharmacology. Birkhäuser, Basel, 117-134.

19. Deakin JFW \& Graeff FG (1991). 5-HT and mechanisms of defence. Journal of Psychopharmacology, 5: 305-315.

20. Beck AT (1976). Cognitive Therapy of the Emotional Disorders. New American Library, New York.

21. Clark DM (1989). Anxiety states: panic and generalized anxiety. In: Hawton K, Salkovkis PM, Kirk J \& Clark DM (Editors), Cognitive Behaviour Therapy for Psychiatric Problems: a Practical Guide. Oxford Medical Publications, Oxford, 52-96.

22. Kidman A (1989). Neurochemical and cognitive aspects of anxiety disorders. Progress in Neurobiology, 32: 391-402.

23. Depaulis A \& Bandler RJ (1991). The Midbrain Periaqueductal Gray Matter: Functional, Anatomical and Neurochemical Organization. Plenum Press, New York.

24. Davis M (1992). The role of the amygdala in fear and anxiety. Annual Review of Psychology, 15: 353-375.

25. LeDoux JE (1995). Emotion: clues from the brain. Annual Review of Psychology, 46: 209-235.

26. Edmunds M (1974). Defence in Animals. Longman, Harlow.

27. Ratner SC (1967). Comparative aspects of hypnosis. In: Gordon JE (Editor), Handbook of Clinical and Experimental Hypnosis. Macmillan, New York, 550-587.
28. Blanchard RJ, Blanchard DC, Rodgers RJ \& Weiss SM (1990). The characterization and modelling of antipredator defensive behavior. Neuroscience and Biobehavioral Reviews, 14: 491-496.

29. Blanchard DC, Blanchard RJ, Rodgers RJ \& Weiss SM (1990). Pharmacological and neural control of anti-predator defense in the rat. Aggressive Behavior, 16: 165-176.

30. Pinel JPJ \& Treit D (1983). The conditioned defensive burying paradigm and behavioral neuroscience. In: Robinson T (Editor), Behavioral Approaches to Brain Research. OUP, Oxford, 212-234.

31. DeVry J, Benz U, Schreiber R \& Traber J (1993). Shock-induced ultrasonic vocalization in young adult rats: a novel model for testing putative anti-anxiety drugs. European Journal of Pharmacology, 249: 331339.

32. Winslow JT \& Insel TR (1991). The infant rat separation paradigm: a novel test for novel anxiolytics. Trends in Pharmacological Sciences, 12: 402-404.

33. Blanchard RJ, Blanchard DC, Agullana R \& Weiss SM (1991). Twenty-two kHz alarm cries to presentation of a predator, by laboratory rats living in visible burrow systems. Physiology and Behavior, 50: 967-972.

34. Blanchard RJ \& Blanchard DC (1989). Antipredator defensive behaviors in a visible burrow system. Journal of Comparative Psychology, 103: 70-82.

35. Blanchard RJ, Parmigiani S, Bjornson C, Masuda C, Weiss SM \& Blanchard DC (1995). Antipredator behavior of SwissWebster mice in a visible burrow system. Aggressive Behavior, 21: 123-136.

36. Pinel JPJ \& Mana MJ (1989). Adaptive interactions of rats with dangerous inanimate objects: support for a cognitive theory of defensive behavior. In: Blanchard RJ, Brain PF, Parmigiani S \& Blanchard DC (Editors), Ethoexperimental Approaches to the Study of Behavior. Kluwer, Dordrecht, 137-155.

37. Molewijk HE, Van der Poel AM \& Olivier B (1995). The ambivalent behaviour 'stretched attend posture' as a paradigm to characterize anxiolytic drugs. Psychopharmacology, 121: 81-90.

38. Kaesermann H-P (1986). Stretched attend posture, a non-social form of ambivalence, is sensitive to a conflict-reducing drug action. Psychopharmacology, 89: 31-37. 
39. Garbe CM \& Kemble ED (1994). Effects of prior agonistic experience on risk assessment and approach behavior evoked by familiar and unfamiliar conspecific odors. Aggressive Behavior, 20: 143-149.

40. Blanchard RJ, Yudko EB, Rodgers RJ \& Blanchard DC (1993). Defense system psychopharmacology: an ethological approach to the pharmacology of fear and anxiety. Behavioural Brain Research, 58: 155-165.

41. Hogg S (1996). A review of the validity and variability of the elevated plus-maze as an animal model of anxiety. Pharmacology, Biochemistry and Behavior, 54: 21 30

42. Montgomery KC (1955). The relation between fear induced by novel stimulation and exploratory behavior. Journal of Comparative and Physiological Psychology, 48: 254-260.

43. Handley SL \& Mithani S (1984). Effects of alpha-adrenoceptor agonists and antagonists in a maze-exploration model of 'fear'motivated behaviour. Naunyn Schmiedeberg's Archives of Pharmacology, 327: 15.

44. Pellow S, Chopin P, File SE \& Briley M (1985). Validation of open:closed arm entries in an elevated plus-maze as a measure of anxiety in the rat. Journal of Neuroscience Methods, 14: 149-167.

45. Lister RG (1987). The use of a plus-maze to measure anxiety in the mouse. Psychopharmacology, 92: 180-185.

46. Rex A, Fink H \& Marsden CA (1994). Effects of BOC-CCK-4 and L 365,260 on cortical 5-HT release in guinea-pigs on exposure to the elevated plus-maze. Neuropharmacology, 33: 559-565.

47. Hendrie CA, Eilam D \& Weiss SM (1994). Effects of diazepam and buspirone in two models of anxiety in wild voles (Microtus socialis). Journal of Psychopharmacology, Abstract Book, A46, 181.

48. Yannielli PC, Kanterewicz BI \& Cardinali DP (1996). Daily rhythms in spontaneous and diazepam-induced anxiolysis in Syrian hamsters. Pharmacology, Biochemistry and Behavior, 54: 651-656.

49. Handley SL \& McBlane JW (1993). Multiple serotonin mechanisms in animal models of anxiety: environmental, emotional and cognitive factors. Behavioural Brain Research, 58: 203-210.

50. Moser PC (1989). An evaluation of the plus-maze test using the novel anxiolytic buspirone. Psychopharmacology, 99: 4853.
51. Dawson GR \& Tricklebank MD (1995). Use of the elevated plus-maze in the search for novel anxiolytic agents. Trends in Pharmacological Sciences, 16: 33-36.

52. Treit $D$ (1991). Anxiolytic effects of benzodiazepines and 5- $\mathrm{HT}_{1 \mathrm{~A}}$ agonists: animal models. In: Rodgers RJ \& Cooper SJ (Editors), 5- $H T_{1 A}$ Agonists, 5- $\mathrm{HT}_{3}$ Antagonists and Benzodiazepines: Their Comparative Behavioural Pharmacology. Wiley, Chichester, 107-132.

53. Rodgers RJ (1991). A step in the right direction. Journal of Psychopharmacology, 5: 316-319.

54. Falter U, Gower AJ \& Gobert J (1992). Resistance of baseline activity in the elevated plus-maze to exogenous influences. Behavioural Pharmacology, 3: 123128.

55. Shepherd JK (1992). Preliminary evaluation of an elevated 'zero-maze' as a model of anxiety in laboratory rats. Journal of Psychopharmacology, 6: A56, 223.

56. Adamec RE \& Shallow T (1993). Lasting effects on rodent anxiety of a single exposure to a cat. Physiology and Behavior, 54: 101-109.

57. Lorenz K (1973). The fashionable fallacy of dispensing with description. Naturwissenschaften, 60: 1-9.

58. Tinbergen $N$ (1963). On the aims and methods of ethology. Zeitschrift für Tierpsychologie, 20: 410-433.

59. Thorpe WH (1979). The Origins and Rise of Ethology. Heinemann, London.

60. Lee C \& Rodgers RJ (1990). Antinociceptive effects of plus-maze exposure: influence of opiate receptor manipulations. Psychopharmacology, 102: 507-513.

61. Rodgers RJ, Cole JC, Cobain MR, Daly P, Doran PJ, Eells JR \& Wallis P (1992). Anxiogenic-like effects of fluprazine and eltoprazine in the mouse elevated plusmaze: profile comparisons with $8-\mathrm{OH}-$ DPAT, CGS 12066B, TFMPP and mCPP. Behavioural Pharmacology, 3: 621-634.

62. Treit D, Menard J \& Royan C (1993). Anxiogenic stimuli in the elevated plusmaze. Pharmacology, Biochemistry and Behavior, 44: 463-469.

63. Rodgers RJ \& Johnson NJT (1995). Factor analysis of spatiotemporal and ethological measures in the murine elevated plusmaze. Pharmacology, Biochemistry and Behavior, 52: 297-303

64. Cruz APM, Frei F \& Graeff FG (1994). Ethopharmacological analysis of rat behavior on the elevated plus-maze. Pharmacology, Biochemistry and Behavior, 49: 171-176.
65. Fernandes C \& File SE (1996). The influence of open arm ledges and maze experience in the elevated plus-maze. Pharmacology, Biochemistry and Behavior, 54: 31-40.

66. McCreary AC, McBlane JW, Spooner HA \& Handley SL (1996). 5-HT system and anxiety: multiple mechanisms in the elevated plus-maze. Polish Journal of Pharmacology, 48: 1-12.

67. Trullas R \& Skolnick P (1993). Differences in fear-motivated behaviors among inbred mouse strains. Psychopharmacology, 111: 323-331.

68. Rodgers RJ \& Cole JC (1993). Influence of social isolation, gender, strain and prior novelty on plus-maze behaviour in mice. Physiology and Behavior, 54: 729-736.

69. Holmes A \& Rodgers RJ (1996). Factor analysis of behavioural responses to repeated testing in the plus-maze. Journal of Psychopharmacology, 10 (Suppl): A47, 185.

70. Blanchard RJ, Brain PF, Parmigiani S \& Blanchard DC (1989). Ethoexperimental Approaches to the Study of Behavior. Kluwer, Dordrecht.

71. Rodgers RJ \& Randall JI (1986). Acute non-opioid analgesia in defeated male mice. Physiology and Behavior, 36: 947950

72. Rodgers RJ \& Randall JI (1986) Resident's scent: a critical factor in acute analgesic reaction to defeat experience in male mice. Physiology and Behavior, 37: 317-322.

73. Rodgers RJ \& Randall JI (1987). Benzodiazepine ligands, nociception and defeat analgesia in male mice. Psychopharmacology, 91: 304-315

74. Rodgers RJ \& Randall JI (1988). Blockade of non-opioid analgesia in male mice by selective neuronal and non-neuronal benzodiazepine recognition site ligands. Psychopharmacology, 96: 45-54.

75. Rodgers RJ \& Shepherd JK (1989). Prevention of the analgesic consequences of social defeat in male mice by $5-\mathrm{HT}_{1 \mathrm{~A}}$ anxiolytics, buspirone, gepirone and ipsapirone. Psychopharmacology, 99: 374-380.

76. Rodgers RJ \& Shepherd JK (1992). Attenuation of defensive analgesia in male mice by $5-\mathrm{HT}_{3}$ receptor antagonists, ICS 205-930, MDL 72222, MDL 73147 and MDL 72699. Neuropharmacology, 31: 553-560.

77. Rodgers RJ (1995). Neuropharmacological aspects of adaptive pain inhibition in murine 'victims' of aggression. Aggressive Behavior, 21: 29-39. 
78. Rodgers RJ \& Cole JC (1993). Anxiety enhancement in the elevated plus-maze by immediate prior exposure to social stressors. Physiology and Behavior, 53: 383-388.

79. Cole JC \& Rodgers RJ (1993). An ethological analysis of the effects of chlordiazepoxide and bretazenil (Ro16-6028) in the murine elevated plus-maze. Behavioural Pharmacology, 4: 573-580.

80. Johnson NJT \& Rodgers RJ (1996). Ethological analysis of cholecystokinin $\left(\mathrm{CCK}_{A}\right.$ and $\mathrm{CCK}_{\mathrm{B}}$ ) receptor ligands in the elevated plus-maze test of anxiety in mice. Psychopharmacology, 124: 355-364.

81. Cole JC \& Rodgers RJ (1995). Ethological comparison of the effects of diazepam and acute/chronic imipramine on the behaviour of mice in the elevated plus-maze. Pharmacology, Biochemistry and Behavior, 52: 473-478.

82. Rodgers RJ, Cutler MG \& Jackson JE (1996). Behavioural effects of subchronic chlordiazepoxide, maprotiline and fluvoxamine. II. The elevated plus-maze. Pharmacology, Biochemistry and Behavior (in press).

83. Shepherd JK, Grewal SS, Fletcher A, Bill DJ \& Dourish CT (1994). Behavioural and pharmacological characterization of the elevated zero-maze as an animal model of anxiety. Psychopharmacology, 116: 56-64.

84. Griebel G, Sanger DJ \& Perrault G (1996). The use of the rat elevated plus-maze to discriminate non-selective and BZ-1( $\omega 1)$ selective benzodiazepine receptor ligands. Psychopharmacology, 124: 245254.

85. Rodgers RJ, Cole JC, Aboualfa K \& Stephenson LH (1995). Ethopharmacological analysis of the effects of putative 'anxiogenic' agents in the mouse elevated plus-maze. Pharmacology, Biochemistry and Behavior, 52: 805-813.

86. Dalvi A \& Rodgers RJ (1996). GABAergic influences on plus-maze behaviour in mice. Psychopharmacology, 128: 380397.

87. Rodgers RJ \& Dalvi A (1997). Anxiety, defence and the elevated plus-maze. Neuroscience and Biobehavioral Reviews (in press).

88. Lambert JJ, Belelli D, Hill-Venning C \& Peters JA (1995). Neurosteroids and $\mathrm{GABA}_{A}$ receptor function. Trends in Pharmacological Sciences, 16: 295-303.

89. Rodgers RJ \& Johnson NJT (1996). Neuroactive steroid influences on anxiety. Behavioural Pharmacology, 7 (Suppl 1): 96 (Abstract).
90. Johnson NJT \& Rodgers RJ (1996) Modulation of anxiety-related behaviour in mice by $5 ß$-dihydroprogesterone $(5 ß-$ DHP). Journal of Psychopharmacology, 10 (Suppl): A24, 93.

91. Olivier B, Mos J, van Oorschot R \& Hen $R$ (1995). Serotonin receptors and animal models of aggressive behavior. Pharmacopsychiatry, 28 (Suppl): 80-90.

92. Kemble ED, Thornton AE \& Schultz LA (1987). Some fear-potentiating effects of fluprazine hydrochloride in mice. Aggressive Behavior, 13: 269-280.

93. Cole JC \& Rodgers RJ (1994). Ethological evaluation of the effects of acute and chronic buspirone treatment in the murine elevated plus-maze test: comparison with haloperidol. Psychopharmacology, 114: 288-296.

94. Griebel G, Rodgers RJ, Perrault G \& Sanger DJ (1996). Risk assessment behaviour: evaluation of utility in the study of 5-HT-related drugs in the rat elevated plus-maze test. Pharmacology, Biochemistry and Behavior (in press).

95. Rodgers RJ, Cole JC \& Davies A (1994). Anti-anxiety and behavioural suppressant effects of the novel $5-\mathrm{HT}_{1 \mathrm{~A}}$ receptor agonist, flesinoxan. Pharmacology, Biochemistry and Behavior, 48: 959-963.

96. Cao B-J \& Rodgers RJ (1997). Different behavioural profiles of the $\mathrm{R}(+)$ - and $\mathrm{S}(-)-$ enantiomers of 8-hydroxy-2-(di-npropylamino)tetralin (8-OH-DPAT) in the murine elevated plus-maze. Behavioural Pharmacology (in press).

97. DeVry J (1995). 5-HT 1 A receptor agonists: recent developments and controversial issues. Psychopharmacology, 121: 1-26

98. Fletcher A, Cliffe IA \& Dourish CT (1993). Silent $5-\mathrm{HT}_{1 \mathrm{~A}}$ receptor antagonists: utility as research tools and therapeutic agents. Trends in Pharmacological Sciences, 14: 441-448.

99. Rodgers RJ \& Cole JC (1994). Anxiolyticlike effect of (S)-WAY 100135, a 5-HT1A receptor antagonist, in the murine elevated plus-maze test. European Journal of Pharmacology, 261: 321-325.

100. Cao B-J \& Rodgers RJ (1997). Anxiolyticlike profile of $\mathrm{p}-\mathrm{MPPI}$, a novel $5-\mathrm{HT}_{1 \mathrm{~A}}$ receptor antagonist, in the murine elevated plus-maze. Psychopharmacology (in press).

101. Cao B-J \& Rodgers RJ (1997). Influence of $5-\mathrm{HT}_{1 \mathrm{~A}}$ receptor antagonism on plusmaze behaviour in mice. I. Pindolol enantiomers and pindobind $5-\mathrm{HT}_{1 \mathrm{~A}}$. Pharmacology, Biochemistry and Behavior (in press).
102. Cao B-J \& Rodgers RJ (1997). Influence of $5-\mathrm{HT}_{1 \mathrm{~A}}$ receptor antagonism on plusmaze behaviour in mice. II. WAY 100635 SDZ 216-525 and NAN-190. Pharmacology, Biochemistry and Behavior (in press).

103. File SE \& Gonzalez LE (1996). Anxiolytic effects in the plus-maze of $5-\mathrm{HT}_{1 \mathrm{~A}}$ receptor ligands in dorsal raphe and ventral hippocampus. Pharmacology, Biochemistry and Behavior, 54: 123-128.

104. Andrews N, Hogg S, Gonzalez LE \& File SE (1994). 5-HT 1 A receptors in the median raphe nucleus and dorsal hippocampus may mediate anxiolytic and anxiogenic behaviours, respectively. European Journal of Pharmacology, 264: 259-264.

105. Hodges H, Green S \& Glenn B (1987). Evidence that the amygdala is involved in benzodiazepine and serotonergic effects on punished responding but not discrimination. Psychopharmacology, 92: 491-504.

106. Bill DJ, Knight M, Forster EA \& Fletcher A (1991). Direct evidence for an important species difference in the mechanism of 8-OH-DPAT-induced hypothermia. British Journal of Pharmacology, 103: 1857-1864.

107. Klein DF (1981). Anxiety reconceptualized. In: Klein DF \& Rabkin J (Editors), Anxiety: New Research and Changing Concepts. Raven Press, New York, 235262.

108. Nutt DJ (1990). The pharmacology of human anxiety. Pharmacology and Therapeutics, 47: 233-266.

109. Ballenger JC (1990). The Neurobiology of Panic. Wiley-Liss, New York.

110. Den Boer JA, Westenberg HGM, De Leeuw AS \& van Vliet IM (1995). Biological dissection of anxiety disorders: the clinical role of selective serotonin reuptake inhibitors with particular reference to fluvoxamine. International Clinical Psychopharmacology, 9 (Suppl 4): 4752.

111. Rodgers RJ, Cutler MG \& Jackson JE (1996). Behavioural effects in mice of subchronic buspirone, ondansetron and tianeptine. II. The elevated plus-maze. Pharmacology, Biochemistry and Behavior (in press).

112. File SE \& Zangrossi H (1991). 'One-trial tolerance' to the anxiolytic actions of benzodiazepines in the elevated plus-maze, or the development of a phobic state? Psychopharmacology, 110: 240-244. 
113. Rodgers RJ, Johnson NJT, Norton SJ \& Cole JC (1995). Effects of ritanserin and 1-(2,5-dimethoxy-4-iodophenyl)-2aminopropane (DOI) in the murine elevated plus-maze test of anxiety: an ethopharmacological study. Journal of Psychopharmacology, 9: 38-42.

114. Rodgers RJ, Cole JC \& Tredwell JM (1995). Profile of action of $5-\mathrm{HT}_{3}$ receptor antagonists, ondansetron and WAY 100289 in the elevated plus-maze test of anxiety in mice. Psychopharmacology, 117: 306-312.
115. Rodgers RJ \& Cole JC (1995). The effects of scopolamine and its quaternary analogue in the murine elevated plusmaze test of anxiety. Behavioural Pharmacology, 6: 283-289.

116. Rodgers RJ, Nikulina EM \& Cole JC (1994). Dopamine D1 and D2 receptor ligands modulate the behaviour of mice in the elevated plus-maze. Pharmacology, Biochemistry and Behavior, 49: 985995.

117. Cole JC, Burroughs GJ, Laverty CR, Sheriff NC, Sparham EA \& Rodgers RJ (1995). Anxiolytic-like effects of yohimbine in the murine plus-maze: strain independence and evidence against $\alpha_{2-}$ adrenoceptor mediation. Psychopharmacology, 118: 425-436.
118. Rodgers RJ, Johnson NJT, Champion AJ \& Mills S (1996). Modulation of plusmaze behaviour in mice by the preferential $D_{3}$ receptor agonist, 7-OH-DPAT. Pharmacology, Biochemistry and Behavior, 54: 79-84.

119. Costall B, Hendrie CA, Kelly ME \& Naylor RJ (1987). Actions of sulpiride and tiapride in a simple model of anxiety in mice. Neuropharmacology, 26: 195-200.

120. Dourish CT, Grewal SS, Shepherd JK, Stanhope KJ, Bill DJ \& Fletcher A (1995). Benefits of ethological analysis of behaviour. Trends in Pharmacological Sciences, 16: 260. 